\title{
PEMBANGUNAN MODEL E-LEARNING DI PERGURUAN TINGGI UNTUK MENINGKATKAN EFISIENSI BELAJAR MENGAJAR
}

\author{
Inayatulloh \\ Information Systems Department, School of Information Systems, Binus University \\ Jl. K.H. Syahdan No. 9, Palmerah, Jakarta Barat 11480 \\ inay@binus.ac.id
}

\begin{abstract}
The purpose of this research is to build a model of e-learning for higher education in order to improve the effectiveness of teaching and learning activities. The research method is analyzing the process of learning activities in several universities as a basis for creating a dynamic model of comprehensive e-learning so as to meet the needs of students, lecturers and all parties concerned. In analyzing the teaching-learning process observations at several campuses are conducted to study existing processes and activities. The results are a model of e-learning that can be used by universities in building and developing e-learning applications that already exist.
\end{abstract}

Keywords: model, e-learning, college

\begin{abstract}
ABSTRAK
Tujuan dari penelitian ini adalah membangun sebuah model e-learning di perguruan tinggi guna membangun dan mengembangkan aplikasi e-learning untuk meningkatkan efektifitas kegiatan belajar mengajar. Metode penelitian yang dilakukan adalah dengan melakukan observasi dan menganalisis proses kegiatan belajar di beberapa perguruan tinggi sebagai dasar untuk menciptakan model e-learning yang dibutuhkan sehingga dapat memenuhi kebutuhan mahasiswa, dosen dan semua pihak yang terkait. Hasil yang dicapai adalah sebuah model aplikasi e-learning yang dapat digunakan oleh perguruan tinggi dalam membangun dan mengembangkan aplikasi e-learning yang sudah ada
\end{abstract}

Kata kunci: model, e-learning, perguruan tinggi 


\section{PENDAHULUAN}

Perkembangan teknologi informasi berdampak pada semua aspek kehidupan dari aspek yang sederhana sampai hal besar yang mempengaruhi hajat hidup orang banyak. Salah satu bidang yang sangat dipengaruhi oleh perkembangan teknolgi informasi adalah bidang pendidikan. Di beberapa institusi pendidikan semua kegiatan sudah sangat bergantung pada teknologi informasi mulai dari pendaftaran, proses belajar mengajar, sistem pembayaran, penilaian dan lain sebaginya. Meskipun demikian masih sangat banyak lembaga pendidikan yang menggunakan teknologi informasi hanya untuk mendukung proses belajar mengajar atau biasa disebut $e$-learning system.

Masalah mengemuka ketika para mahasiswa terbentur pada keterbatasan media pembelajaran dimana dengan menggunakan system konvensional mahasiswa dan dosen harus bertatap muka secara fisik. Dengan adanya E-learning maka masalah tersebut dapat di atasi. Masalah lainnya adalah kegiatan perkuliahan yang dilakukan secara konvensional akan terbentur pada data atau informasi yang berhubungan dengan perkuliahan dimana data tersebut dikelola secara manual yang berdampak pada tidak efisienya proses pengolahan data semisal input yang berulang, data tidak terintegrasi dan lain sebagainya.

E-learning merupakan sebuah metode pembelajaran dengan menggunakan teknologi informasi sebagai alat bantu atau pendukung dalam proses belajar mengajar. Dalam konteks penerapannya e-learning tidak hanya digunakan di institusi pendidikan tapi lebih luas lagi digunakan di beberapa perusahaan sebagai media pelatihan atau training, upgrading karyawan dan lain sebgainya. Sebagai sebuah sarana pendukung maka e-learning dapat saja menjadi salah satu faktor keberhasilan pembelajaran di sebuah perguruan tinggi jika pengelolaanya didasarkan pada sebuah rencana strategis jangka panjang. ketidakberhasilan e-learning dapat disebabkan oleh banyak faktor dan akan menjadi bahan evaluasi bagi perguruan tinggi.

E-learning, e-education, atau online learning mengacu pada cara orang berkomunikasi dan belajar secara elektronik yang akhir-akhir ini muncul sebagai satu-satunya kunci untuk mencapai keunggulan kompetitif didalam lingkungan yang penuh dengan informasi (Roffe, 2002: 40). Elearning juga dapat diartikan sebagai penciptaan dan pendistribusian pengetahuan melalui penyampaian informasi, komunikasi, pendidikan, dan pelatihan secara online (Wild et al., 2002: 371). Definisi lain dari e-learning adalah penyampaian pelatihan dan pendidikan melalui interaksi jaringan dan dari kumpulan pengetahuan dan distribusi teknologi yang lain (Fry, 2001: 234).

E-learning membawa proses perubahan dalam proses belajar mengajar. Proses belajar mengajar yang tadinya lebih bersifat teacher-centred approach (pendekatan pembelajaran yang berfokus pada guru) menjadi student-centred approach (pendekatan pembelajaran yang berfokus pada murid). Dalam teacher-centred approach, guru merupakan gerbang informasi yang menyebarkan pengetahuan kepada para muridnya sehingga murid lebih bersikap pasif dengan menerima segala apa yang diberikan oleh guru atau pengajarnya. Disini murid tidak berkesempatan untuk mendapatkan informasi yang benar dan belajar untuk menggunakan kemampuan berfikir dalam level yang lebih tinggi, seperti menganalisis, menyaring, serta mengevaluasi untuk penyebaran informasi kepada orang lain. Hal ini akan berkebalikan dengan student-centred approach. Pendekatan ini percaya bahwa murid adalah peserta aktif dan dapat mengembangkan pengetahuan mereka sendiri dengan cara berinteraksi dengan informasi yang ada. Pandangan ini menempatkan murid sebagai pusat dari proses pembelajaran dan meyakini bahwa guru adalah penasihat, penunjuk arah, fasilitator atau pemandu yang membantu murid untuk mengakses, mengatur, membangun, dan mentransfer informasi untuk memecahkan suatu masalah. Jadi, dalam pendekatan ini murid akan mendapatkan keuntungan tidak hanya dalam konteks yang sedang dipelajari, akan tetapi juga mendapatkan keuntungan dari proses 
pembelajaran, misalnya saja bagaimana cara untuk belajar melalui penemuan, penyelidikan, dan pemecahan masalah (Bose, 2003: 194).

Dikarenakan dalam e-learning yang menjadi pusat pembelajaran serta yang memegang peranan terbesar adalah murid atau pelajar, yang pertama kali perlu diperhatikan dalam proses pengembangan pembelajaran menggunakan e-learning adalah pelajar itu sendiri. Dalam tahap awal proses e-learning, biasanya pengembangan sarana teknis serta berbagai media pendukunglah yang didahulukan, baru kemudian mencari siapa yang mau serta mampu untuk menggunakannya. Padahal seharusnya hal yang paling utama untuk diperhatikan adalah dari segi pelajar itu sendiri. Hal ini mencakup kebutuhan pelajar, riwayat pembelajaran pelajar, tujuan pelajar dalam pembelajaran, isi pembelajaran yang menjadi minat pelajar, serta pertanyaan apakah e-learning lebih memotivasi pelajar daripada proses pembelajaran tradisional. Kesuksesan e-learning terutama dipengaruhi oleh sikap pelajar itu sendiri terhadap situasi pembelajaran (Littig, 2006: 89).

Kadang sering muncul beberapa kesalahpahaman dalam pelaksanaan e-learning. Beberapa orang berpendapat bahwa e-learning berarti menaruh semua pengetahuan dalam komputer. Pelajar dapat belajar dimanapun dan kapanpun mereka suka, hanya mempelajari apa yang mereka butuhkan serta dapat belajar dengan cara yang optimal. Kadang kita lupa bahwa sebenarnya pembelajaran adalah suatu proses sosial. Sekalipun pembelajaran dilakukan dalam kelas, proses pembelajaran ini justru terjadi diluar kelas antar pelajar itu sendiri. Oleh karena itulah, kadang pembelajaran dapat berlangsung dengan baik apabila pembelajaran dengan mediasi komputer digabungkan dengan kelas virtual, kelompok belajar, tugas kelompok, kegiatan off-line, serta bimbingan online dari pengajarnya (Bose, 2003: 194).

Wild et al. (2002: 376) menyatakan bahwa dalam pelaksanaan e-learning bukan berarti konsep pembelajaran tradisional benar-benar ditinggalkan. Dalam pelaksanaan e-learning, karakteristik pembelajaran tradisional yang sesuai dapat dipakai untuk melengkapi karakteristik dari online learning. Beberapa karakteristik tersebut dapat dilihat dari Tabel 1. Dengan menggabungkan kedua konsep tersebut diharapkan akan tercipta hasil pembelajaran yang lebih optimal.

Tabel 1 Penyajian Pengetahuan untuk E-Learning (Wild et al., 2002)

\begin{tabular}{ll}
\hline \multicolumn{1}{c}{ Karakteristik pembelajaran tradisional } & \multicolumn{1}{c}{ Karakteristik online learning } \\
\hline Mengikut sertakan pengajar sepenuhnya & E-learning harus interaktif \\
Mendorong pengembangan kemampuan cognitif & E-learning harus membuat sarana untuk mengulang \\
Menggunakan pengalaman dan pengetahuan terdahulu & dan berlatih \\
dari seorang pengajar & E-learning harus menghasilkan pilihan dari berbagai \\
Menggunakan masalah sebagai stimulus pembelajaran & gaya presentasi \\
Menggunakan aktivitas pembelajaran yang mendorong & Isi dari e-learning harus relevan dan praktis \\
kerjasama antar anggota tim & Pembagian informasi melalui e-learning harus akurat \\
& dan layak untuk dilakukan \\
\hline
\end{tabular}

Agar menjadi sebuah sarana pengetahuan yang efektif, perlu dikembangkan suatu kerangka pengembangan e-learning. Kerangka tersebut meliputi kesiapan organisasi dalam menerapkan $e$ learning (meliputi infrastruktur, budaya organisasi, sikap karyawan atau pelajar. Serta kebutuhan pengetahuan), perancangan isi e-learning yang layak untuk digunakan, perancangan penyajian $e$ learning yang layak, serta pertimbangan dalam implementasi e-learning (Wild et al., 2002: 374).

Dalam perkembangannya, online learning dapat dibedakan menjadi dua model dasar, yaitu campus-based model serta distance based model. Campus-based model memandang media online sebagai pelengkap untuk model penyampaian tradisional, sedangkan distance-based model 
memandang online learning sebagai pengganti untuk bentuk penyampaian tradisional. Distancebased model dapat berbentuk campuran (media campuran, termasuk cetakan, CD, DVD dan yang lainnya, atau mengkombinasikan semua itu dengan pertemuan langsung) atau dapat juga berbentuk pure play (eksklusif secara online, dengan semua bahan pembelajaran melalui internet) (Ennew dan Fernandez-Young, 2006: 148).

Online learning yang digunakan sebagai pengganti penyampaian tradisional memerlukan pertimbangan yang lebih matang daripada online learning yang digunakan hanya sekedar sebagai pelengkap penyampaian tradisional. Keterbatasan pemahaman serta pengetahuan mengenai apa yang sebenarnya diinginkan oleh pasar (pelajar atau karyawan) serta penerapan tujuan yang kurang jelas akan menimbulkan posisi organisasi yang tidak jelas dalam pasar itu sendiri. Selain itu menentukan tujuan untuk jangka panjang juga dapat mendukung keberhasilan dari online learning itu sendiri (Ennew dan Fernandez-Young, 2006: 155).

Pelaksanaan e-learning membutuhkan umpan balik dari para pelakunya. Selain itu, pengajar harus bekerja lebih keras dalam membangun komunitas online, serta lebih melibatkan para pelajar dalam perancangan pembelajaran (Slotte dan Herbert, 2006: 30). Sehingga dalam prakteknya, perlu pertimbangan dari semua pihak yang terkait agar pelaksanaan serta hasil dari e-learning dapat optimal serta sesuai dengan pencapaian yang diinginkan.

\section{METODE}

Berdasarkan hasil observasi ke beberapa perguruan tinggi yang belum menggunakan $e$ learning, proses belajar mengajar dapat dijelaskan seperti Gambar 1 di bawah ini.

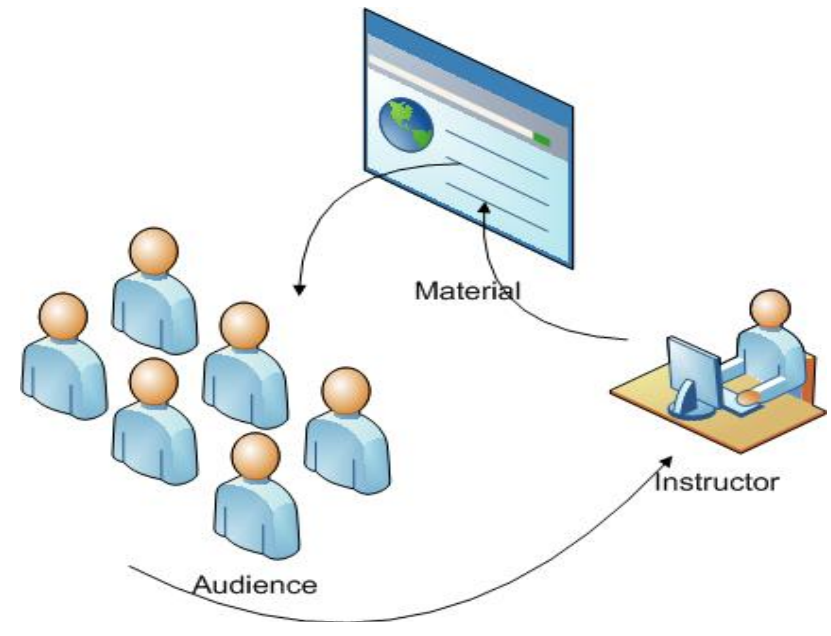

Gambar 1 Proses belajar mengajar

Pada gambar di atas dapat dijelaskan proses atau interkasi antara instruktur dan audience dalam sebuah kegiatan belajar mengajar atau pelatihan dimana seorang instruktur menjelakan materi dari satu sumber kemudian audience atau mahasiswa mendengarkan dan menyimak materi yang disampaikan.

Instruktur telah mempersiapkan materi atau bahan ajar kemudian menampilkannya pada papan tulis dan menjelaskan kepada audience. Kegiatan lain seperti diskusi atau tanya jawab juga dilakukan 
pada tempat dan waktu yang sama demikian juga latihan dan pengumpulan tugas dilakukan pada waktu dan tempat yang sama.

Setelah mempelajari system berjalan kemudian dilakukan wawancara tentang pembanguan aplikasi e-learning sebagai solusi dari masalah yang ada. Para mahasiswa dan dosen mengharapkan adanya sebuah system yang menjadi media untuk menyimpan dan membagikan materi, media untuk mengirim tugas , mengelola data perkuliahan secara online dan lain sebagainya.

\section{HASIL DAN PEMBAHASAN}

Gambar 2 di bawah ini merupakan model e-learning system yang dibangun.

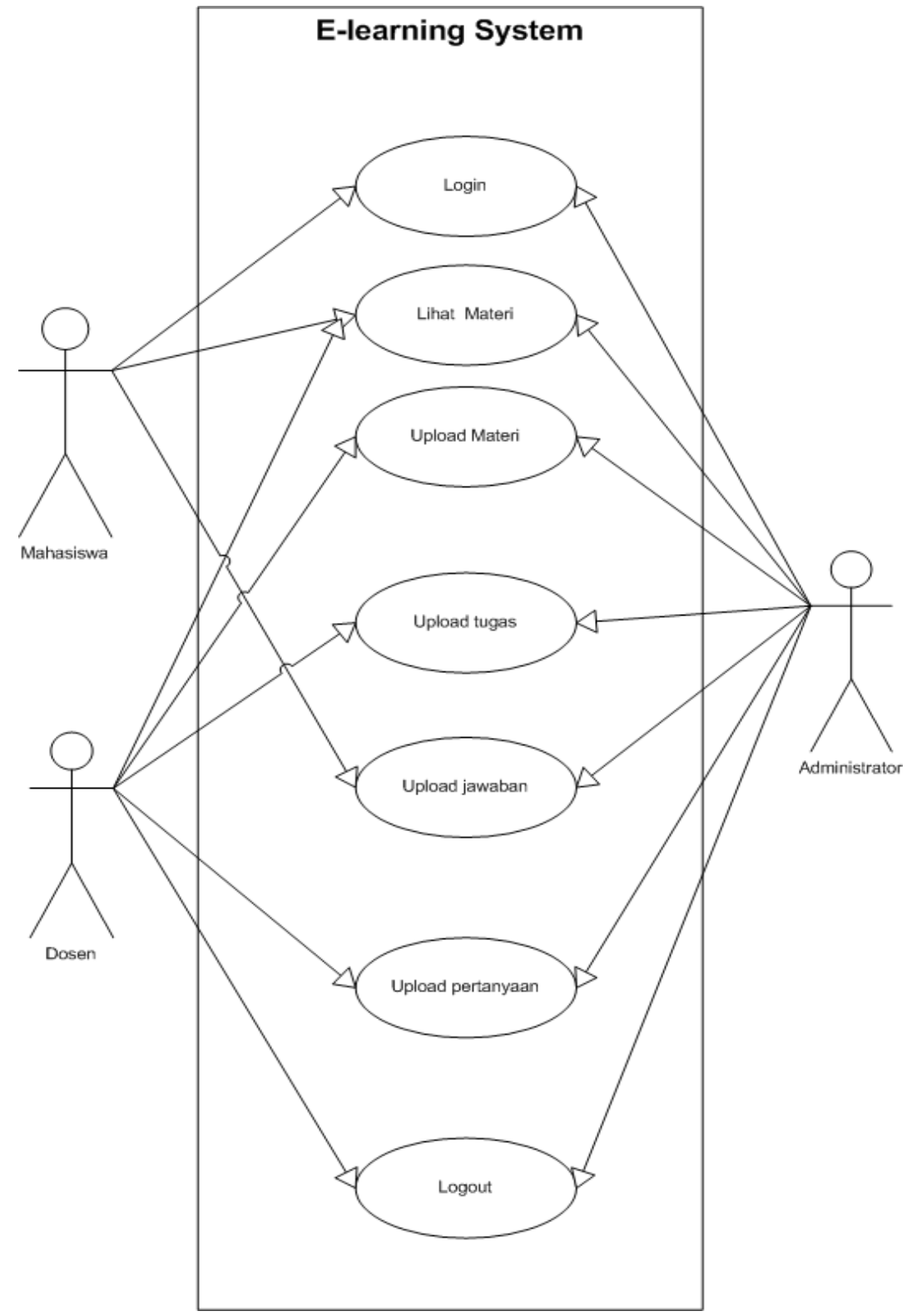

Gambar 2 Model e-learning system 
Gambar diatas menjelaskan sebuah system e-learning yang mengintegrasikan kegiatan belajar mengajar secara online. Masing-masing user di berikan password untuk bisa melakukan login dan melakukan aktifitas yang berbeda tergantung pada otoritas masing-masing.

Admin dapat melakukan upload materi dan mengelola data dan informasi yang berhubungan dengan perkuliahan. Dosen dan mahasiswa dapat melihat materi dan upload serta download tugas.

\section{PENUTUP}

Berdasarkan hasil bahasan aplikasi front office dan back office dari seluruh user, yaitu mahasiswa, dosen dan admin pada aplikasi ini terintegrasi pada satu sistem e-learning. Hal ini akan sangat membantu dosen dan mahasiswa dalam melakukan kegiatan belajar mengajar secara online dan memudahkan admin dalam mengelola data dan informasi mengenai kegiatan belajar mengajar.

Sistem ini membantu lembaga pendidikan untuk dapat meningkatkan efektifitas dan efisiensi proses pembelajaran secara online dimana peningkatan efisiensi dan efektifitas tersebut akan meningkatkan kinerja perguruan tinggi atau lembaga tersebut secara keseluruhan

\section{DAFTAR PUSTAKA}

Bose, Kabita. (2003). An e-learning experience: a written analysis based on my experience in an $e$ learning pilot project. Campus-Wide Information Systems, 20 (5), 193 - 199.

Ennew, Christine T. Anita Fernandez-Young. (2006). Weapons of mass construction? the rethoric and reality of online learning. Marketing Intelligence and Planning, 24 (2), 148 - 157.

Fry, Kate. (2001). E-learning markets and providers: some issues and prospects. Education + Training, 43 (4/5), 233 - 239.

Littig, Peter. (2006). New-media supported learning today and tomorrow: recommendations for the next generation of education and training concepts supported by new learning media. Industrial and Commercial Training, 38 (2), 86 - 92.

Roffe, Ian. (2002). E-learning: engagement, enhancement, and execution. Quality Assurance in Education, 10 (1), 40 - 50.

Slotte, Virpi. Anne Herbert. (2006). Online learning vs print learning, which provides the better result? Development and Learning in Organizations, 20 (6), 29 - 31. 